\title{
Evidência e informação: desafios da medicina para a próxima década
}

\section{Renata Ciol}

\section{Doutoranda em Medicina Interna e Terapêutica e Medicina Baseada em Evidências da UNIFESP}

Vera Silvia Marão Beraquet

\section{Professora Doutora da Faculdade de Biblioteconomia da PUC-Campinas}

Aborda a explosão informacional e os avanços da Medicina que culminaram na Medicina Baseada em Evidências (MBE), que vem alterando a prática médica rumo ao uso constante da evidência científica atual e contextualizada na decisão clínica. A MBE pode ampliar o papel do profissional da informação para além da busca de informação, permitindo seu envolvimento com a seleção e avaliação crítica da literatura nos moldes da biblioteconomia clínica, onde o bibliotecário é considerado parte integrante das equipes multidisciplinares de saúde.

Palavras-chave: Medicina Baseada em Evidências; Biblioteconomia Clínica; Formação Bibliotecária.

\section{Evidence and information: the challenges for Medicine in the next decade}

This paper addresses the explosion of information and the advances in medicine that have contributed to the rise of Evidence-Based Medicine (EBM) which has been changing medical practice towards the constant use of current scientific evidence in the clinical decision-making. EBM can also expand the role of the information professional beyond information search, allowing his/her involvement in the selection and critical evaluation of the literature, according to the clinical librarianship model where the librarian is considered an integral part of multidisciplinary health teams. 
Keywords: Evidence-based Medicine; Clinical

Librarianship; Librarian Education.

Recebido em 11.12.2008 Aceito em 04.12.2009

\section{Introdução}

Na Saúde, a cronologia da ocorrência dos primeiros experimentos ainda na Antigüidade, ao surgimento da Medicina com Hipócrates (400 a.C.) até o momento atual constituem eventos que têm registrado 0 interesse e a fascinação humana sobre o corpo, a vida, a doença e a morte. O grande salto da área deu-se na Idade Média, particularmente com o surgimento das primeiras universidades (Bologna e Montpéllier), que dedicavam grande ênfase à área médica, institucionalizando nas academias a pesquisa em saúde.

O campo da Medicina vem avançando a passos largos desde Pasteur e a penicilina, e mais recentemente com a descoberta da estrutura do DNA; exemplos que sinalizam que nas próximas décadas a Medicina será diferente do que é hoje, especialmente considerando-se os avanços da engenharia genética, da farmacologia, de novos modelos de prática clínica e da tecnologia da informação; que a cada dia surpreendem com novas vacinas e terapêuticas, cirurgias mais precisas e menos invasivas, bem como com novos meios de acesso, armazenagem e recuperação da informação.

O médico do século XXI já vislumbra os efeitos dessa sociedade da informação, onde a explosão informacional é um de seus mais expoentes símbolos, acarretando uma avalanche de conhecimentos novos, não podendo ser acompanhada pela velocidade digital.

O aumento exponencial de documentos, aliado à necessidade dos profissionais da saúde de encontrarem o melhor, mais barato, mais adequado e mais eficaz tratamento ao paciente, tem alterado radicalmente o paradigma clínico, fazendo com que o médico se veja obrigado a incorporar a informação científica na sua decisão clínica.

As experiências na Guerra Civil Espanhola e na II Guerra Mundial causaram grande impacto no médico Archie Cochrane, que, na década de setenta do século $X X$, pleiteou que todo o tratamento efetivo de saúde deveria ser gratuito e de livre acesso, chamando a atenção para a falta de resumos críticos em saúde organizados e atualizados periodicamente. Cochrane semeou as bases de um projeto para reunir toda a literatura científica sobre determinado assunto de saúde e elaborar resumos contendo todos os resultados, de forma que pudessem ser facilmente interpretados pelos clínicos durante o cuidado com o paciente. A essa compilação metodologicamente estruturada, deu-se o nome de revisão sistemática, que tem como finalidade reunir, num documento único e de fácil compreensão, a melhor evidência sobre uma determinada questão clínica que estava dispersa em várias pesquisas mundo afora. 
Nesse cenário, em 1991 surgem as primeiras sinalizações do movimento conhecido como Medicina Baseada em Evidências (MBE), que, segundo Sackett et al. (1996), define-se como o uso consciente, explícito e crítico da melhor evidência atual, integrado com a experiência clínica e os valores e as preferências do paciente. A consolidação do termo, porém, foi idealizada pelo grupo do pesquisador Gordon Guyatt, da McMaster University Medical College, no Canadá. Na atualidade, o movimento expandiu-se e é possível encontrar inclusive a expressão "saúde baseada em evidências".

A MBE não substitui a experiência e o raciocínio clínico do médico, pois a sensibilidade, o conhecimento e a comunicação com o paciente são ainda mais fundamentais quando se tem também acesso às evidências científicas. A experiência clínica é crucial e necessária, mas deve ser somada a evidências científicas. Não se pode utilizar a MBE para vender tecnologia de equipamentos ou para priorizar novos medicamentos lançados pela indústria farmacêutica. Em outras palavras, a MBE não toma decisões, pois são as pessoas que decidem, e não as evidências.

Como a Ciência da Informação se envolve nesse processo? A interdisciplinaridade da área possibilita seu envolvimento com todos os campos do saber, organizando o conhecimento para torná-lo acessível, disponível e, o que é mais relevante, utilizável.

Os profissionais da informação devem ser capazes de reconhecer e considerar papéis e oportunidades não tradicionais de atuação, bem como as habilidades e competências desejáveis e os princípios norteadores para cada atuação, considerando a interdisciplinaridade da Ciência da Informação.

A base de conhecimento da Biblioteconomia, envolvida com a organização do conhecimento em todas as áreas, está se voltando para uma forte interdisciplinaridade, que integra diversas perspectivas sobre o fazer da profissão, e que precisa cruzar as barreiras artificiais entre as disciplinas do conhecimento, mostrando toda a inter-relação e interdependência entre elas (BERAQUET, 1981).

Para a Medicina Baseada em Evidências, é fundamental o uso de resultados de pesquisas clínicas de qualidade no atendimento ao paciente; - que implica incorporar à experiência médica as habilidades de recuperação da informação (busca em bases de dados), avaliação crítica dessa informação e, por conseqüência, aplicação da evidência no contexto individual do paciente, informando-o sobre benefícios e possíveis riscos (NOBRE; BERNARDO, 2007).

Utilizar os métodos da MBE não garante resultados mais favoráveis, porém melhora a chance de acertos da medicina. Para Coomarasamy e Khan (2004), o ensino da medicina baseada em evidências valoriza, no contexto informacional, a habilidade de encontrar e avaliar criticamente a informação, o uso da informação segundo a individualidade do paciente, bem como o comportamento de busca da informação por parte do profissional da saúde. 
É sabido, porém, que os profissionais da saúde, notadamente os médicos, carecem de tempo para fazer as buscas, e de capacitação para realizar essa tarefa com a competência desejada.

Cursos de pesquisa em bases de dados da saúde são oferecidos nas faculdades de medicina e em instituições como a BIREME, entretanto não se consegue ensinar aos médicos todas as estratégias de busca existentes. Essa é uma expertise do bibliotecário, profissional da informação preparado para trabalhar com as evidências e com o referencial teórico das áreas nas quais atua, utilizando a formação em Ciência da Informação para encontrar, organizar e tratar essa informação.

A exigência para médicos e demais profissionais da saúde (incluindo gestores das várias instâncias do Sistema Único de Saúde) de tomarem decisões fundamentando-se na evidência científica; a explosão informacional; a escassez de tempo desses profissionais; e sua pouca familiaridade com as bases de dados são aspectos indicados na literatura como razões para a ação do profissional da informação junto às equipes multidisciplinares de saúde.

Bibliotecários brasileiros inseridos na Saúde atuam, em sua maior parte, no setor acadêmico. Os poucos encontrados na área clínica fundamentam suas atividades na prática, sem uma visão reflexiva baseada em conhecimento científico. Trata-se de uma ação incipiente e localizada especialmente em universidades.

As novas oportunidades de atuação fora das bibliotecas, como integrantes das equipes de saúde, vêm sendo implementadas especialmente na Inglaterra e nos Estados Unidos, graças ao desenvolvimento e à expansão da Medicina Baseada em Evidências (MBE), em que o profissional da saúde tem experimentado decidir sobre 0 cuidado com o paciente com base na melhor evidência científica disponível naquele momento.

O Centro Cochrane do Brasil, criado em 1996, consolida-se como elemento essencial no que se refere à qualificação de profissionais para atuarem com a MBE. Sua missão, como seção brasileira da Colaboração Cochrane, é elaborar, manter e divulgar revisões sistemáticas de ensaios clínicos randomizados, colaborando para a tomada de decisões em Saúde.

A revisão sistemática constitui um resumo da literatura médica que utiliza métodos explícitos para sistematicamente buscar, criticamente avaliar e sintetizar a literatura mundial sobre um assunto específico, com o objetivo de minimizar todos os vieses e erros (SACKETT, 1996). Tratase de revisão da literatura com método rigoroso, avaliação crítica e síntese dos resultados relevantes sobre determinada questão clínica. 0 profundo rigor metodológico utilizado na elaboração de uma revisão sistemática garante a qualidade dos resultados, e pode até minimizar o risco de vieses e fraudes nas pesquisas. A revisão sistemática pode ou não incluir metanálise, método estatístico que integra os resultados dos estudos originais incluídos na revisão.

O vasto e complexo campo da informação em saúde revela que não existe uma parceria efetiva entre bibliotecários e outros profissionais de saúde, porque se faz necessária uma interação entre as atividades de 
cada um em busca do melhor atendimento às demandas de saúde, nos moldes do que se denomina biblioteconomia clínica.

O bibliotecário clínico, como é conhecido nos Estados Unidos e em alguns países da Europa, corresponde ao profissional da informação que atua fora do espaço físico das bibliotecas, como parte integrante das equipes multiprofissionais de saúde de hospitais.

Esse profissional atua nas equipes clínicas e fornece aos médicos e demais membros das equipes dos hospitais informações que lhes permitam a melhor decisão sobre os pacientes, fundamentada na melhor evidência científica disponível, contribuindo para o melhor atendimento à população. Ocupa-se da recuperação e transferência da informação, segundo as necessidades dos usuários, num papel de mediador dessa informação, e não mais apenas de intermediário.

Mesmo nesses países, são vários os modelos de biblioteconomia clínica, considerando-se que sua prática tem forte relação de dependência com o contexto em que é aplicada.

No caso brasileiro, as orientações do SUS têm alterado a prática dos profissionais da saúde e dos gestores, e podemos dizer que também a dos bibliotecários inseridos nesse sistema, porque, na estrutura descentralizada, nosso sistema de saúde aponta para a integração de equipes multiprofissionais e a organização do fluxo de trabalho (e de informação) entre elas.

A biblioteconomia clínica pode constituir uma referência para a atuação interdisciplinar dos profissionais dessas duas áreas em nosso país, porém é essencial encontrar os fundamentos para essa prática no contexto brasileiro de saúde. Isso implica buscar nesses modelos o que deu certo, as dificuldades e resistências para sua implementação, bem como os resultados alcançados.

A idéia principal é fortalecer a provisão e a aplicação da informação em Saúde, melhorando a interação entre seus profissionais e os serviços de saúde, diminuindo a lacuna entre o que a Academia produz e o que é efetivamente trazido para a prática.

A medicina baseada em evidências (MBE) pode ampliar o papel do profissional da informação - bibliotecário clínico - para além da busca da literatura, rumo ao envolvimento com a prática e à capacitação para a seleção da literatura de qualidade e a avaliação crítica dessa literatura (LAPPA, 2004). A informação, portanto, constitui ponto focal na evolução do conceito da MBE.

A MBE tem sido uma resposta favorável à enorme expansão em tamanho e escopo da informação científica, na tentativa de auxiliar principalmente os médicos a encontrarem a informação que possa lhes garantir o melhor atendimento a seus pacientes (Sackett, 1996).

Entretanto, como funciona a MBE? São consideradas cinco etapas para sua prática, a saber:

1. formulação de uma pergunta (necessidade de informação) sobre prevenção, diagnóstico, tratamento ou prognóstico;

2. busca na literatura da melhor evidência científica para responder a essa questão; 
3. avaliação crítica dessa evidência com relação à sua validade, impacto e aplicabilidade;

4. integração da avaliação crítica com a experiência clínica e a individualidade e os valores do paciente;

5. avaliação da eficiência na execução das etapas 1 a 4, buscando meios de se aprimorar na vez seguinte.

A utilização das ferramentas e dos processos da Medicina Baseada em Evidências vem sendo enfatizada na educação, na pesquisa e na prática clínica. Enquanto o princípio de que a medicina deve ser baseada na melhor evidência científica não é novo, os meios para alcançar esse princípio têm sido formalizados com a MBE por meio da integração da melhor evidência disponível com a experiência e intuição do médico e os valores do paciente (TRIVEDI, 2007).

No cenário da saúde, o bibliotecário clínico pode colaborar com o processo de gestão do conhecimento em hospitais. A biblioteconomia clínica foi criada nos EUA há mais de trinta anos, quando Lamb, em 1971, abordou a necessidade de prover informação específica aos médicos dentro das equipes de saúde (SARGEANT; HARRISON, 2004), para diminuir a distância entre o conhecimento produzido pela medicina e o realmente utilizado pelo médico.

O bibliotecário clínico vem gradualmente desenvolvendo um novo padrão de serviços de informação dentro de hospitais dos sistemas de saúde dos EUA e Europa. Profissionais norte-americanos saíram das bibliotecas para trabalhar em ambientes clínicos no início dos anos 70; e, na Inglaterra, a primeira tentativa de biblioteconomia clínica se deu no começo dos anos 80, no Departamento de Cirurgia do Guys Hospital de Londres.

Vale ressaltar a experiência brasileira pouco conhecida entre nós, do Programa de Biblioteconomia Clínica implantado pela Fundação Pioneiras Sociais, no Hospital das Doenças do Aparelho Locomotor de Brasília, em 1983, e que não teve continuidade (SILVA, 1986). Anos mais tarde, Martínez-Silveira (2005) abordou o assunto ao investigar o comportamento informacional de médicos residentes, de um hospital universitário da Bahia, no uso da informação para a prática clínica, verificando, nesse processo, o papel do bibliotecário. Dentre as conclusões, a autora acredita que não serão as bibliotecas tradicionais a suprirem com excelência as necessidades de informação de médicos, e sim os bibliotecários especializados inseridos nos diferentes contextos.

No hospital, o bibliotecário clínico é o profissional que leva a biblioteca ao usuário, antecipa suas questões e busca entregar ao profissional da saúde a informação adequada; o que, segundo Lipscomb (2000), confirma o objetivo da biblioteconomia clínica como o de reforçar a missão da própria biblioteconomia: tornar a informação relevante disponível no momento em que é solicitada.

Considerando-se que as atividades bibliotecárias tradicionais também incluem o serviço de referência, a busca em bases de dados, a familiaridade com a tecnologia de informação e a capacitação de usuários, podemos inferir que a diferença entre o bibliotecário da área médica 
(atuando basicamente em bibliotecas) e o bibliotecário clínico reside na presença deste último nas equipes de saúde, com atividades que serão definidas segundo as circunstâncias locais onde atua.

O trabalho de Martínez-Silveira (2005), no entanto, mostrou que, no caso de médicos-residentes, as necessidades informacionais não parecem estar próximas do nível da informação científica atualizada, mas sim da informação consolidada, a informação básica que forma o conhecimento médico. Para a autora, o comportamento real desses profissionais é procurar os médicos-preceptores, e não a coleção da biblioteca ou os bibliotecários que, em nenhum momento "ocupam lugar importante nas preferências dos médicos-residentes quando se fala em fontes de informação" (p. 129).

Esse fato compromete inclusive a adoção, nos hospitais, de estratégias de $\mathrm{MBE}$, fazendo com que a produção e a difusão do conhecimento médico sejam também problemas de saúde coletiva e das ciências sociais (CAMARGO JR., 2003).

O papel a ser ocupado pelo bibliotecário clínico é o de um especialista com diferentes habilidades e conhecimentos, que leva à equipe de saúde a melhor e mais atualizada evidência científica, clinicamente relevante e aplicável ao problema em questão.

Apesar das competências necessárias aos bibliotecários reconhecidas e discutidas na literatura (ASCHROFT, 2002; BANKS et al., 2005), não existem pesquisas suficientes no Brasil que tratem dessa questão com a profundidade necessária para refletir-se na prática de seus profissionais, que precisam adaptar-se aos diferentes segmentos aos quais estarão expostos na sua jornada.

Uma pesquisa de Sargeant e Harrison (2004) apontaram as seguintes habilidades necessárias ao bibliotecário clínico: construção e manutenção de boa relação profissional com médicos, capacidade de fazer perguntas, capacidade de aprender, interesse nas questões clínicas e científicas.

Incluem também a utilização das tecnologias de informação, competências para captar e tratar a informação estratégica, capacidade de síntese, desenvolvimento de serviços de informação específicos e de trabalho em equipes multidisciplinares (FLORANCE et al., 2002; WALTER, 2005).

Espera-se também do bibliotecário clínico o conhecimento de disciplinas clínicas, de anatomia e fisiologia, o conhecimento de termos e descritores médicos, a capacidade de gerenciar projetos, a experiência com buscas em bases de dados, o conhecimento da prática baseada em evidências e de métodos de pesquisa, assim como de noções de epidemiologia.

Beraquet (2007), investigando bibliotecários clínicos do Reino Unido, verificou que o treinamento do bibliotecário no local de trabalho e a experiência no trabalho são as variáveis que mais contribuem para a aquisição de competências; e que o bom relacionamento de trabalho entre bibliotecários e profissionais da saúde é essencial para o sucesso da biblioteconomia clínica. Foram consideradas fundamentais: capacidade de 
avaliar recursos de informação, educação continuada, avaliação crítica da literatura, síntese da literatura e comunicação da melhor evidência.

O bibliotecário clínico deve estar apto a interagir efetivamente com outros profissionais de saúde, ser capaz de avaliar uma necessidade clínica e responder rapidamente com informações relevantes que apóiem as decisões, cumprindo os papéis de agente de informação e de educador (LAPPA, 2004).

\section{Considerações}

Os desafios que se apresentam nesse momento se referem tanto à Medicina quanto à Ciência da Informação, principalmente no que diz respeito ao ensino e à atuação dos profissionais formados nas duas áreas.

No caso da Medicina, é preciso superar a eventual deficiência teórica e prática em seu processo de ensino-aprendizagem, em busca da criação de um ambiente aprendiz que motive os alunos para a educação continuada. O médico, por sua vez, deve saber trabalhar em equipe e adquirir habilidades para buscar, recuperar e avaliar criticamente a literatura, características essenciais para a prática da Medicina Baseada em Evidências.

Como já comentado, é necessário diminuir a distância entre o conhecimento produzido em saúde e o conhecimento utilizado na prática médica rotineira (know-do), o que implica o uso efetivo da evidência para solucionar um problema específico da rotina clínica.

Entretanto, o entendimento e a aceitação da Medicina Baseada em Evidências não podem constituir um fato isolado das faculdades de medicina e de algumas sociedades médicas. Requer-se como fundamental a determinação política do governo rumo a uma medicina não apenas mais eficaz e efetiva, mas também mais equânime, que realmente reflita os princípios do Sistema Único de Saúde.

A prática da biblioteconomia clínica ainda não existe no Brasil, porém a complexidade da biblioteconomia voltada para a saúde possibilita, no caso brasileiro, que inúmeros trabalhos busquem um salto qualitativo para a Ciência da Informação, de forma a contribuir, num futuro próximo, para o reconhecimento por parte da sociedade do papel que pode ser exercido pelo bibliotecário no campo da saúde.

A biblioteconomia clínica pode ser o primeiro passo para que o profissional da informação deixe de modo gradual as bibliotecas médicas (universitárias) para ir ao encontro das reais demandas informacionais de usuários, médicos, gestores, pacientes e demais profissionais da informação.

Ao refletir sobre o papel das escolas médicas e de biblioteconomia na atualidade, é possível vislumbrar algumas ações de sua responsabilidade:

1. preparar os docentes para a construção coletiva do conhecimento, em que o aluno possa ser ator participativo desse processo;

2. criar condições para que o ensino seja baseado em evidências; 
3. disseminar a prática da pesquisa desde os primeiros anos da graduação, para que se torne um ato natural; e

4. promover um ambiente favorável ao trabalho multidisciplinar, por meio de projetos de pesquisa que envolvam as duas áreas.

É possível também expandir a visão desses profissionais sobre a implementação da prática da biblioteconomia clínica, ainda inexistente no país, e abrir novas frentes de pesquisa sobre a atuação do bibliotecário brasileiro no século XXI.

\section{Referências}

ASCHROFT, L. Developing competencies, critical analysis and personal transferable skills in future information professionals. Library Review, $\mathrm{v}$. 53, n. 2, p. 82-88, 2004.

BANKS, M. A. et al. Complementary competencies: public health and health sciences librarianship. J. Med. Libr. Assoc., v. 93, n. 3, p. 338-347, Jul. 2005.

BERAQUET, V. S. M. The development and significance of the core curriculum in archives, library and information studies. Loughborough, 1981. (Thesis Doctoral) - Loughborough University of Technology, 1981.

- Bases para a implantação da biblioteconomia clínica em um hospital universitário de Campinas, SP. Brasília: CNPq, 2007. Relatório de pesquisa de pós-doutorado.

CAMARGO JR., K. R. Sobre palheiros, agulhas, doutores e o conhecimento médico: o estilo de pensamento dos clínicos. Cad. Saúde Pública, Rio de Janeiro, v. 19, n. 4, p. 1163-1174, jul./ago. 2003.

COOMARASAMY, A.; KHAN, K. S. What is the evidence that postgraduate teaching in evidence based medicine changes anything? A systematic review. BMJ, v. 39, p. 1017-1021, 2004.

FLORANCE, $V$. et al. Information in context: integrating information specialists into practice settings. J Med Libr Assoc, v. 90, n. 1, p. 49-58, Jan. 2002.

LAPPA, E. Clinical librarianship (CL): a historical perspective. Electronic Journal of Academic and Special Librarianship, v. 5, n. 2-3, Fall 2004. Disponível em: <http://southernlibrarianship.icaap.org/content/v05n02/lappa_e01.htm>. Acesso em: 10 set 2008.

LIPSCOMB, C. E. Clinical librarianship (Historical Notes). Bull Med Libr Assoc, v. 88, n. 4, p. 393-395, Oct. 2000.

MARTÍNEZ-SILVEIRA, M. S. A informação científica na prática médica: estudo do comportamento do médico-residente. 184f. Salvador, 2005. Dissertação (Mestrado em Ciência da Informação) - Instituto de Ciência da Informação, Universidade Federal da Bahia, Salvador, 2005. 
NOBRE, M.; BERNARDO, W. Prática clínica baseada em evidência. Rio de Janeiro: Elsevier, 2007.

SACKETT, D. L. et al. Evidence based medicine: what it is and what it isn't. BMJ, v. 312, p. 71-72, 13 jan. 1996.

SARGEANT, S. J. E.; HARRISON, J. Clinical librarianship in the UK: temporary trend or permanent profession? Part I: a review of the role of the clinical librarian. Health Information and Libraries Journal, v. 21, p. 173-181, 2004.

SILVA, C. M. S. Biblioteconomia clínica em uma unidade hospitalar. $R$. Bibliotecon. Brasília, Brasília, v. 14, n. 2, p. 299-303, jul./dez. 1986.

TRIVEDI, M. Knowledge management in health science libraries. Electronic Journal of Academic and Special Librarianship, v. 8 n. 2, Summer 2007. Disponível em: <http://southernlibrarianship.icaap.org/content/v08n02/trivedi_m01.html >. Acesso em: 10 set 2008.

WALTER, M. T. A formação do profissional da informação relacionada às tecnologias de informação: os bibliotecários na perspectiva da literatura, reflexões. Enc. Bibli: R. Eletr. Bibliotecon. Ci. Inf., Florianópolis, n. 19, 1. Sem., p. 1-20, 2005. 